\title{
Correction to: Does C-reactive protein day 1 post-surgery have a predictive role for post-operative complications: a single-centre perspective following published meta-analysis
}

Murray Williams ${ }^{1} \cdot$ Fiona Langlands ${ }^{2} \cdot$ Mathew Giles $^{3}$

Published online: 5 December 2019

(C) Springer Science+Business Media, LLC, part of Springer Nature 2019

Correction to: Obesity Surgery

https://doi.org/10.1007/s11695-019-04241-4

The first sentence of the article should read as follows:

Bona et al. (2019) have published a review and Bayesian meta-analysis to investigate the predictive utility of $\mathrm{C}$ reactive protein (CRP) for detecting post-operative complications following bariatric surgery. [1]

The first two sentences of the third paragraph should read as follows:

We have re-analysed our data set at the York Teaching Hospital with this cut off $(61 \mathrm{mg} / \mathrm{l})$ to give a single centre perspective on this result. One hundred patients had a POD 1 CRP.

Publisher's note Springer Nature remains neutral with regard to jurisdictional claims in published maps and institutional affiliations.

The online version of the original article can be found at https://doi.org/ 10.1007/s11695-019-04241-4

Murray Williams

mo.richard.williams@gmail.com

1 Anaesthetic Department, York Teaching Hospital NHS Foundation Trust, Wigginton Road, York YO31 8HE, UK

2 Department of Surgery, Bradford Teaching Hospitals NHS Foundation Trust, Duckworth Lane, Bradford BD9 6RJ, UK

3 Department of Surgery, York Teaching Hospital NHS Foundation Trust, Wigginton Road, York YO31 8HE, UK 